\title{
Characterization on Performance, Morphologies and Molecular Properties of Dual-Surfactants Based Polyvinylidene Fluoride Ultrafiltration Membranes
}

\author{
Abdul Rahman Hassan ${ }^{1,2^{\star}}$, Che Wan Insyirah Che Wan Takwa', Nurul Hannan Mohd Safari', \\ Sabariah Rozali', Nor Azirah Sulaiman ${ }^{1}$

\footnotetext{
1 East Coast Environmental Research Institute, Universiti Sultan Zainal Abidin, 21300 Kuala Nerus, Terengganu, Malaysia

2 Faculty of Innovative Design and Technology, Universiti Sultan Zainal Abidin, 21300 Kuala Nerus, Terengganu, Malaysia

* Corresponding author, e-mail: rahmanhassan@unisza.edu.my
}

Received: 10 February 2019, Accepted: 06 June 2019, Published online: 15 July 2019

\begin{abstract}
This paper addressed the pioneering work on the effects of dual surfactants component on the performance, morphologies and molecular properties of polyvinylidene fluoride/polyether glycol (PVDF/PEG 200) ultrafiltration (UF) membranes. The PVDF surfactant membranes were prepared via dry/wet via phase inversion technique with the addition of sodium dodecyl sulfate (SDS)/Tween 80 and Triton X-100/ Tween 80 into polymer solution. Experimental data revealed that the dual surfactants improved the membrane performance up to $120.84 \mathrm{~L} / \mathrm{m}^{2} \times \mathrm{h}$ and $82 \%$ of permeate flux and rejection of bovine serum albumin, respectively. In addition, $2 \mathrm{wt} \%$ of dual surfactants also found to induce the growth of fine finger-like and macro-voids cavities inside the membranes while the FTIR spectra proved that the existence of dual surfactants in PVDF membranes produced better molecular alignment which contributed significantly towards better flux and good rejection. In conclusion, the used of dual surfactants in the PVDF ultrafiltration membranes improved the performanceproperties of the membranes and extending the possibly versatile for the membrane to be used for more applications.
\end{abstract}

Keywords

polyvinylidene fluoride membrane, dual surfactant, morphology, bovine serum albumin, egg albumin

\section{Introduction}

Membrane technology has vast applications in various industrial processes, namely in waste treatment $[1,2]$, food and biotechnology industries [3], metal industries [4], textile industries [5-7], chemical process industries [8], water production [9] and bacteria/virus removal applications [10]. In general, membranes can be classified based on their morphologies including dense homogenous polymer membranes, porous membranes and thin-film composite membranes [11]. The polymeric porous membranes for UF, nanofiltration (NF) and reverse osmosis (RO) commonly fabricated via phase inversion technique [12-14]. The produced porous membrane structures can either symmetric (isotropic) or asymmetric (anisotropic) membrane as reported by Ladewig and Al-Shaeli [11] and Gallucci et al. [15]. The asymmetric membrane consists of a thin layer (skin) and porous substrate layer whereby the skin layer plays an important part as a selective barrier layer and provides major resistance to the feed solution $[12,16]$. The polymer solutions undergo solidification proses after being immersed in a water bath (liquid-liquid de-mixing) [17]. Then the nascent film separated into a polymer-rich and a polymer-lean phase after the solvent of the casting solution exchanged with the non-solvent from the coagulation bath [18]. At this level, few types of membrane structures can be formed, i.e., a symmetric structure with uniform porosity, an asymmetric structure with thick macro-porous, spongy sub-layer or an asymmetric structure with finger-like and larger voids [19].

The morphological structure also considered as one of the crucial parts in ensuring the competency of the membrane. Several researchers revealed that there are various factors can be monitored in order to control the membrane structures. It is including the solvent selection in the solution system [20], the concentration and types of polymer [21], the types of non-solvent system [22], introduction of small amount of additive such as organic, inorganic additive, surfactant, polymer, mineral fillers, etc. into the system [19-23] and control the condition of the film casting [8]. 
In this paper, PVDF material was selected to be used as the main polymer in the membrane fabrication. This is owing to its good characteristic in terms of excellent chemical resistance, strong mechanical properties as well as high thermal stability [24]. The polymer also exhibits good competitive thermal and chemical stability, mechanical properties and radiation resistance [18, 25]. PVDF based membrane is hydrophobic, which restraint its usefulness and advantages. Basically, membrane fouled after the adsorption of solute and other molecules in the feed stream onto the membrane surface whereby reduced the efficiency of the performance and the life span of the membrane [26]. The addition of hydrophilic materials into the PVDF polymeric solution may reduce the hydrophobicity as well as improved the level of the membrane hydrophilicity. Pezeshk et al. [27] reported that by blending polyethylene glycol, PEG (hydrophilic additive) into the solution system, the permeability of the membrane and polyethylene oxide (PEO) rejection significantly increased. The addition of a small amount of PEG could suppress the cell growth rate in the membrane, which eventually reduced the pore size and increased the porosity.

The addition of additive alone is still not versatile enough to fabricate desirable membrane properties and structure with higher performances. Few types of surfactant could be used as membrane materials, such as ionic and non-ionic surfactant. Mansourpanah et al. [28] investigated the effects of cetyltrimetyl ammonium bromide (CTAB) as cationic surfactant, Triton X-100 as non-ionic surfactant and sodium dodecyl sulfate (SDS) as anionic surfactant on the properties of poly(piperazine amide) thin film composite (TFC) membranes. The outstanding variations were pointed up in the presence of Triton X-100 and SDS, but considerable unchanged in the presence of CTAB surfactant. Besides, the effects of Tween 20 concentration (non-ionic surfactant) towards TEP/PVDF membrane on the performance and properties morphology were studied by Chang et al. [29]. The team discovered that the presence of Tween 20 in the composition system promoted the filtrate flux meanwhile the rejection profiles was decreased. Aside from that, the effects of Tween 80 and Span 80 on Poly(methyl methacrylate) membranes were revealed could initiate or suppress the development of macro-voids based on the degree of the miscibility between these surfactants and coagulant [30]. The water content, membrane porosity and pure water permeation increased after the addition of Tween 80 in Polyethersulfone (PES) membranes, while decreased the solute rejection [21].
Even though many studies have been done on the use of surfactants in the research work, there is no article reporting the effects of dual surfactants (combination of surfactants) on the performance, morphologies and properties of polymeric membrane. Besides, the effect of single surfactant in the PVDF membranes was discussed previously in [12].

Therefore, this study is so significant towards a better understanding on the effect of dual surfactants materials for performance modification and properties improvement for the membrane to be more applicable for different applications.

\section{Materials and method \\ 2.1 Materials}

Poly(vinylidene fluoride), (PVDF, Kynar ${ }^{\circledR}$ from Arkema, $\mathrm{Mw}=45.00 \mathrm{~g} / \mathrm{mol}, \mathrm{d}=1.78 \mathrm{~g} / \mathrm{cm}^{3}$ ) was purchased in the form of pellet. N-methyl-2-pyrrolidone (NMP >99\%, Merck, Darmstadt, Germany, $\mathrm{d}=1.00 \mathrm{~g} / \mathrm{cm}^{3}$ ) was used as the solvent in the membrane solution. Polyethylene glycol, (PEG 200, supplied by Sigma Aldrich) used as an additive material. Sodium dodecyl sulfate, (SDS, Mw $=288.37 \mathrm{~g} /$ mol, anionic), Tween 80 ( $\mathrm{d}=1.060-1.090 \mathrm{~g} / \mathrm{cm}^{3}$, non-ionic) were supplied from Merck Schuchardt OHG, Germany and Triton X-100 (Mw = $646.86 \mathrm{~g} / \mathrm{mol}$, non-ionic) from Fisher Chemical were used as surfactants. Ethanol, n-hexane and distilled water were used as the coagulation bath and post-treatment purposed. Bovine serum albu$\min (\mathrm{BSA}, \mathrm{Mw}=69 \mathrm{kDa})$ and egg albumin $(\mathrm{EA}, \mathrm{Mw}=$ $45 \mathrm{kDa}$ ) obtained from Acros Organics, USA were used as the solute for ultrafiltration test. Disodium hydrogen phosphate $\left(\mathrm{Na}_{2} \mathrm{HPO}_{4}\right)$ and sodium phosphate monobasic monohydrate $\left(\mathrm{NaH}_{2} \mathrm{PO}_{4} \cdot \mathrm{H}_{2} \mathrm{O}\right)$ were used as a buffer solution to prepare the protein feed samples and the preparation is referred as in the previous article [12].

\subsection{Membrane preparation}

PVDF/PEG/surfactants membranes were prepared via phase inversion method. PVDF and PEG 200 were blending in NMP solvent under a constant stirring for 8 hours at $55{ }^{\circ} \mathrm{C}-60{ }^{\circ} \mathrm{C}$, in the presence of dual surfactants. A set of polymer solutions prepared by varying the combination of surfactants as showed in Table 1 and assigned as MUF1 (without surfactant), MUF2 (SDS/Tween 80) and MUF3 (Triton X-100/Tween 80). The homogenous membrane solutions cooled for at least 2 hours to eliminate air bubbles before casting process. The polymeric solutions were cast on a dry glass plate uniformly, with aid of casting knife 
Table 1 Formulation of PVDF based UF membranes

\begin{tabular}{lcccccc}
\hline Membrane & $\begin{array}{c}\text { PVDF } \\
(\mathrm{wt} \%)\end{array}$ & $\begin{array}{c}\text { NMP } \\
(\mathrm{wt} \%)\end{array}$ & $\begin{array}{c}\text { PEG } \\
200 \\
(\mathrm{wt} \%)\end{array}$ & SDS & $\begin{array}{c}\text { Triton } \\
\text { X-100 }\end{array}$ & $\begin{array}{c}\text { Tween } \\
80\end{array}$ \\
\hline MUF1 & 17 & 80 & 3 & 0 & 0 & 0 \\
MUF2 & 17 & 78 & 3 & 1 & 0 & 1 \\
MUF3 & 17 & 78 & 3 & 0 & 1 & 1 \\
\hline
\end{tabular}

maintaining a similar clearance or gap between the knife and the glass. Then, $180 \mu \mathrm{m}$ of nascent membrane film on the glass plate immersed in a water bath (coagulation) and let the precipitation process to take place and complete. The films detached from the glass plate after some time and immersed the film for one day in water before soaked it into ethanol and n-hexane solvent for 24 hours and 2 hours, respectively. The dry membranes were cut into desired shape and size to fit into the filtration cell.

\subsection{BSA and EA separation}

In order to study the effects of dual surfactants on the permeate flux and solute rejection, $0.1 \mathrm{wt} \%$ of BSA (69 kDa) and EA ( $45 \mathrm{kDa})$ proteins were prepared in $0.5 \mathrm{M}$ of phosphate buffer ( $\mathrm{pH}$ 7.2). The test was carried out in dead-end mode by using Solvent Resistant Stirred Cell (UF CellXFUF 047 01-Model, Milipore, USA) with a membrane diameter of $42 \mathrm{~mm}$, tighten with a rubber O-ring and a Teflon coated magnetic paddle. Effective area of the disk membranes is $1.3856 \times 10^{-3} \mathrm{~m}^{2}$.

The experiment was set up as in Fig. 1 and conducted under a steady state flow at $25{ }^{\circ} \mathrm{C}$ and $300 \mathrm{kPa}$ of operational pressure with $250 \mathrm{ml}$ of protein samples. The protein experiment was operated up to 1 hour of separation. During the analysis, the permeate solutions were collected (flux test; Eq. (1)) and examined for protein concentration using UV-Vis spectrophotometer at wavelength $280 \mathrm{~nm}$ (rejection percentage; Eq. (3)). The experiments were repeated three times of analysis for triplication and all the experimental data of fluxes and rejection are the average values of the membranes performance.

$J v=\left(\frac{V}{A \times t}\right)$

where $J v$ is the permeate flux $\left(\mathrm{L} / \mathrm{m}^{2} \times \mathrm{h}\right), V$ is the volume of permeate solution collected (L), $A$ is the effective area of membrane $\left(\mathrm{m}^{2}\right)$ and $t$ is the time $(\mathrm{h})$.

$$
R=\left(1-\frac{C p}{C f}\right) \times 100
$$

where $R$ is rejection of protein (\%), $C p$ is the concentration of protein in permeates $(\mathrm{mg} / \mathrm{mL})$ and $C f$ is the concentration of protein in the feed $(\mathrm{mg} / \mathrm{mL})$.

\subsection{Morphological analysis by SEM}

The membrane samples were analyzed by using Scanning Electron Microscope (SEM-JEOL JSM-6360LA). Crosssectional images were observed at various magnifications in the range of $350 \mathrm{X}-800 \mathrm{X}$. The samples were broken in liquid nitrogen and appropriate sizes of broken membranes were attached to a sample holder using tapes. The samples coated with gold, using Auto Fine Coater (JFC-1600) to enhance electronic conductivity. The details of morphological structures (pore lengths and widths) are the average values that measured from 15 measuring points based on the SEM images during the SEM analysis $[12,31]$.

\subsection{Molecular study by FTIR}

The orientation of molecule in the membrane samples were examined by transmission Variance 3100 FTIR Excalibur Series. The sample was mounted into the sample holder with 'skin layer' of the sample facing the IR beam. The spectra were recorded with cumulating 32 scans in total within the wave number of $4000-1000 \mathrm{~cm}^{-1}$. The analysis was performed at $2 \mathrm{~cm}^{-1}$ of resolution.

\section{Result and discussion}

\subsection{UF membranes for BSA and EA Separation}

Bovine serum albumin (BSA) and egg albumin (EA) was test for UF experiment. The influence of dual anionic/ non-ionic and non-ionic/non-ionic surfactants on permeates flux and protein rejections are depicts in Figs. 2 and 3, meanwhile, From Fig. 2, the addition of both ionic/ non-ionic (MUF2 membrane) and non-ionic/non-ionic (MUF3 membrane) surfactants enhanced the permeate

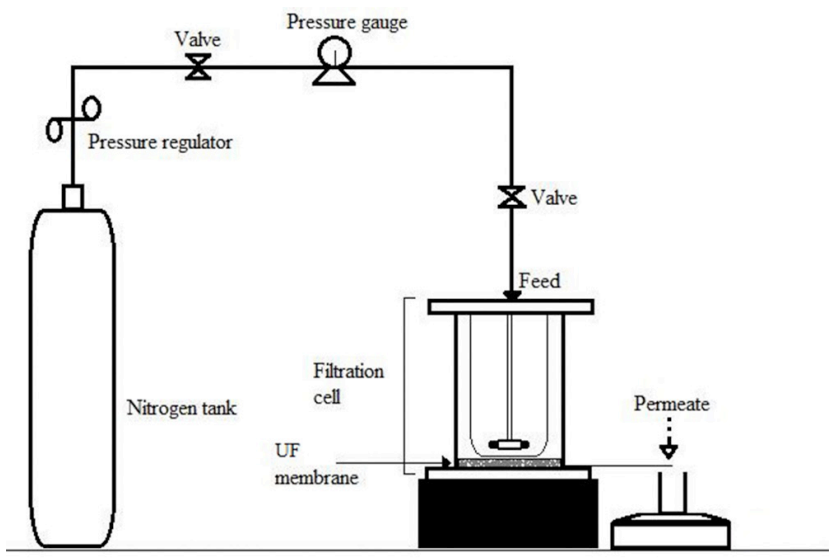

Fig. 1 Experimental set-up of ultrafiltration (UF) testing 


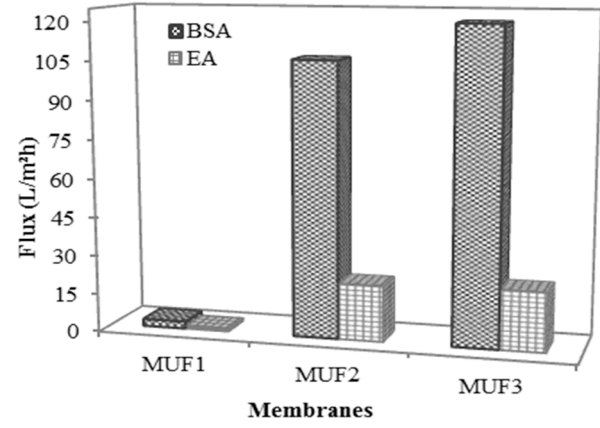

Fig. 2 Permeate fluxes of BSA and EA protein for PVDF/PEG 200 UF membranes with the addition of dual surfactants

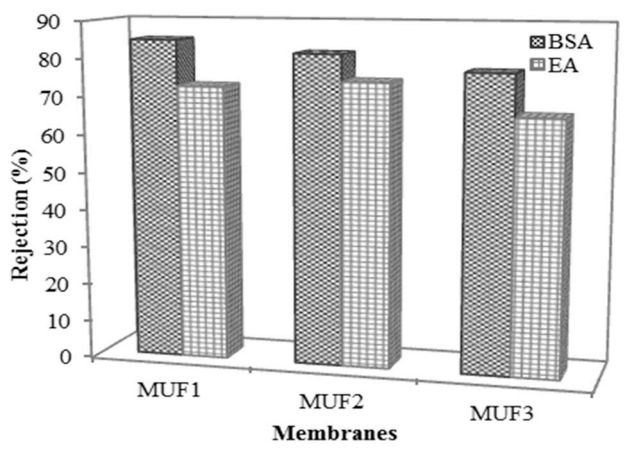

Fig. 3 BSA and EA protein separation for PVDF/PEG 200 UF membranes with the addition of dual surfactants

flux of BSA and EA proteins. MUF1 membrane exhibited the lowest BSA and EA fluxes which are $2.74 \mathrm{~L} / \mathrm{m}^{2} \times$ h and $1.03 \mathrm{~L} / \mathrm{m}^{2} \times \mathrm{h}$, respectively.

Meanwhile, MUF3 membrane (non-ionic/non-ionic surfactants) achieved the highest BSA and EA fluxes, which are $120.84 \mathrm{~L} / \mathrm{m}^{2} \times \mathrm{h}$ and $23.01 \mathrm{~L} / \mathrm{m}^{2} \times \mathrm{h}$, respectively. These data depicted that the combination of non-ionic/non-ionic surfactants in a polymeric solution resulted in a different behavior. The interaction between the non-polar sites of the membranes and hydrophobic chain were observed and resulted into hydrophilization of the membrane surface and pores [32]. This phenomenon directly led to higher permeability compared to the other membranes.

Fig. 3 shows the result of BSA and EA protein rejection for the MUF1, MUF2 and MUF3 membranes. Experimental data showed that the MUF1 (without surfactant) obtained the highest BSA and EA rejection which are $85 \%$ and $78 \%$, respectively. As the addition of PEG 200 reduced the membrane pores and pore size, solutes with higher molecular weight than the pore size of the membrane is retained which thus exhibited the lowest permeate flux and achieved the highest proteins rejection.

BSA and EA rejection for MUF2 membrane were $82 \%$ and $75 \%$, which are higher than MUF3 membrane.
The results demonstrated that the existence of anionic/ non-ionic surfactants in a dope formulation solution caused direct interact with hydrophobic regions in the membrane surface. Meanwhile, the rejections of BSA and EA for MUF3 were found to be of about $78 \%$ and $67 \%$, respectively. The mixing of both non-ionic surfactants usually used to prevent proteins aggregation due to agitation or shaking. The protein molecules difficult to compete for hydrophobic surfaces such as air-water interfaces, thus inhibiting proteins molecules from unfolding at these hydrophobic polymeric membrane interfaces [33].

\subsection{Morphological analysis of dual surfactants in PVDF membranes}

Fig. 4 (a)-(c) are the cross-sectional structure of MUF1, MUF2 (SDS/Tween 80) and MUF3 (Triton X-100/Tween 80) membranes, respectively. The typical membranes containing PVDF/PEG 200 are having asymmetric structure, i.e., a dense top surface layer (skin layer), a porous sub-layer (support layer), and a small portion of sponge-like structure $[14,34]$. Based on the SEM images in Fig. 4 (a)-(c), finger-like cavities beneath the top skin layer and larger voids (macro-voids) near the bottom surface were fully developed. The formation of finger-like cavities is the result from instantaneous de-mixing due to high mutual affinity of solvent to water [35]. As the polymer solution containing PEG 200, it was formed a thin film between the solution and the air interface as soon as they are exposed to the air. The solvents located between polymer chains can be rapidly diffused out and the skin layer of the asymmetric membrane become denser. Addition of PEG 200 into casting solution, the spongy structures was produced from the fast flow out into coagulation bath. According to Kim and Lee [36], the rapid outflow rate offers macro-voids, porous interconnecting channels of the sponge-type.

The existence of PEG additives in the casting solutions has two effects. (i) The dissolution of PEG consumed some of the solvent and led to higher viscosity of membrane casting solutions. The membrane dope becomes thermodynamically less stable, which resulted in rapid instantaneous de-mixing when the membrane dope is immersed into the coagulation bath. (ii) The hydrophilicity of PEG in the membrane dope affects the exchange rate of solvent and non-solvent during phase inversion process and influences the precipitation kinetics and the formation of resulting membrane morphology consequently [35].

Best to our knowledge, there is no researcher reporting on the effects of dual surfactant towards membrane 

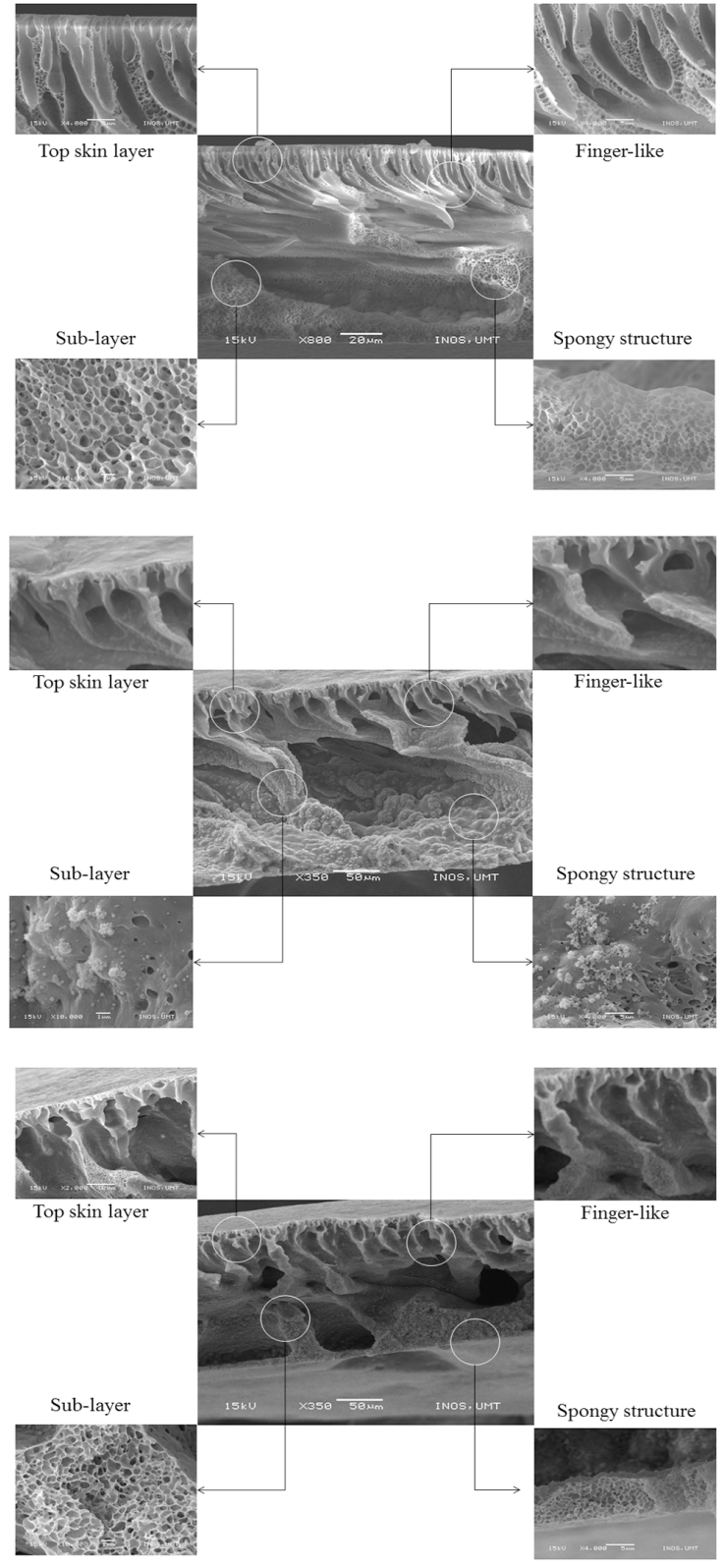

Fig. 4 Cross-sectional structure of (a) MUF1; (b) MUF2 (SDS/ Tween 80); (c) MUF3 (TritonX-100/Tween 80) membranes

performance, morphologies and molecular properties. As in Fig. 4 (b), MUF2 membrane that fabricated from (SDS/ Tween 80) produced finger-like and macro-voids structures with better interconnection between the blending materials. Several researchers reported that surfactants either anionic or non-ionic were able to speed-up the phase de-mixing process and led to enhancement of macro-voids structure [29, 37]. In addition, the present of $2 \mathrm{wt} \%(1: 1)$ of SDS/Tween 80 formed more macro-voids which occupied most of the membrane sub and bottom layers. Similar result of single surfactant (SDS, Triton X-100 and CTAB) was reported by Buch et al. [38].
Meanwhile, MUF3 membrane produced from blending of (Triton X-100/Tween 80) showed larger macro-voids at bottom membrane layer. This led towards highest flux as the surfactants are highly solvable mutually which directly exchange upon their contact during the immersion process. According to Chang et al. [29], the pores started to growth on the top surface (skin) of the membrane after the fabrication process when $1 \mathrm{wt} \%$ of Tween 80 is added into the dope solution. The observation of membrane pores are actually penetrated through the pore in the cross section which connected to the skin layer of the membrane. Chang et al. [29] revealed that by varying Tween-20 content in the dope, it is possible to vary the quantity as well as the pore size on the top surface, and the porosity in bulk of the prepared membrane. For the use of surfactants, Triton X-100 and Tween 80 as non-ionic surfactants would be expected to show no electrostatic interaction and instead may interact with polymer solely by hydrophobic bonding [39].

In Table 2, MUF1 membrane shows the highest protein rejection of about $85 \%$ due to the smallest pore length, finger-like structures, macro-voids length and width properties of about $1.11 \mu \mathrm{m}, 40.93 \mu \mathrm{m}, 4.07 \mu \mathrm{m}, 130.13 \mu \mathrm{m}$, and $26.57 \mu \mathrm{m}$, respectively. Beside, MUF3 exhibited the highest permeate flux due to the largest finger-like length and width of about 86.0 and $19.0 \mu \mathrm{m}$, respectively. Moreover, morphological details in Table 2 also proved that the addition of dual surfactants into PVDF membrane led towards larger pore details which significantly produced the membrane with higher flux and good rejection.

\subsection{Molecular properties of dual surfactants in PVDF membranes}

Figs. 5-7 show the IR spectra of MUF1, MUF2 and MUF3 PVDF ultrafiltration membrane, respectively. Generally, the membranes showed typical spectra of PVDF material. It can be seen from the figures, a strong peak of $\mathrm{C}-\mathrm{F}$

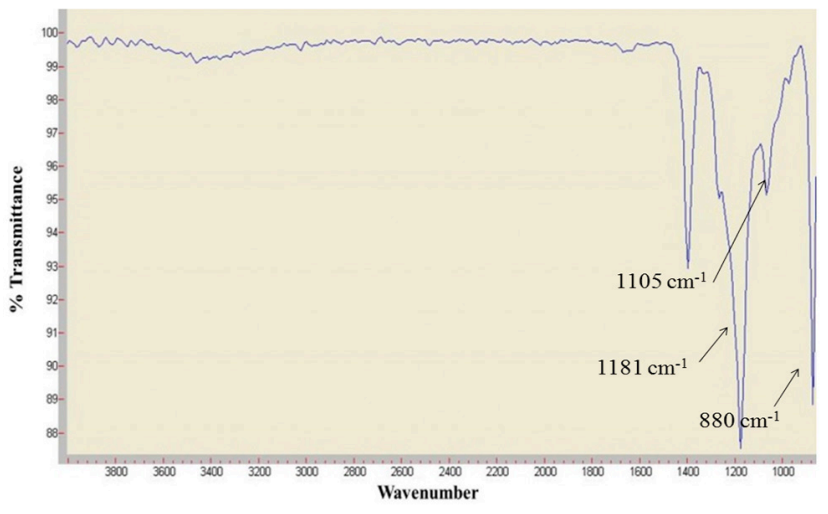

Fig. 5 FTIR spectra of MUF1 membrane 
Table 2 Membrane morphological details for PVDF/PEG/surfactants membranes

\begin{tabular}{lcccccc}
\hline Membrane & $\begin{array}{c}\text { Finger-like } \\
\text { Length }(\mu \mathrm{m})\end{array}$ & $\begin{array}{c}\text { Finger-like } \\
\text { Width }(\mu \mathrm{m})\end{array}$ & $\begin{array}{c}\text { Macro-voids } \\
\text { Length }(\mu \mathrm{m})\end{array}$ & $\begin{array}{c}\text { Macro-voids } \\
\text { Width }(\mu \mathrm{m})\end{array}$ & $\begin{array}{c}\text { Pore Length } \\
(\mu \mathrm{m})\end{array}$ & $\begin{array}{c}\text { Pore Width } \\
(\mu \mathrm{m})\end{array}$ \\
\hline MUF1 & $40.93 \pm 1.9$ & $4.07 \pm 0.2$ & $130.13 \pm 2.1$ & $26.57 \pm 0.6$ & $1.11 \pm 0.10$ & $1.18 \pm 0.09$ \\
MUF2 & $67.23 \pm 2.1$ & $16.83 \pm 0.7$ & $139.33 \pm 2.0$ & $77.39 \pm 0.5$ & $1.17 \pm 0.07$ & $1.03 \pm 0.06$ \\
MUF3 & $86.17 \pm 1.0$ & $19.30 \pm 0.8$ & $138.13 \pm 2.0$ & $58.43 \pm 0.7$ & $1.19 \pm 0.07$ & $1.08 \pm 0.05$ \\
\hline
\end{tabular}

stretch and C-C-C asymmetric stretch were showed at wavenumber of $1175-1180 \mathrm{~cm}^{-1}$ and $880 \mathrm{~cm}^{-1}$ indicated the interaction of PVDF in the membrane [40]. Beside, C-O bond stretch at $1105 \mathrm{~cm}^{-1}$ was observed and indicated the existence of PEG additive in the fabricated membranes. Even the infrared spectra of all PVDF membranes demonstrated of same functional group, the addition of surfactants showed a better molecular alignment.

Figs. 6 and 7 illustrate IR spectra of MUF2 and MUF3 membranes, respectively. IR spectra in these figures do not showed significant changes compared to MUF1 membrane due to similar chemical solutions used as the base materials in membrane making. However in Fig. 6, a new peak at $1274 \mathrm{~cm}^{-1}$ was detected which assigned to an asymmetric vibration of $\mathrm{S}=\mathrm{O}$ from sulfone group of anionic surfactant of SDS. Meanwhile in Fig. 7, the combination of non-ionic/non-ionic surfactant in the polymeric membrane exhibits new peak at $1664 \mathrm{~cm}^{-1}$ referred to $\mathrm{C}=\mathrm{O}$ stretch of Tween 80 and Triton $\mathrm{X}-100$. FTIR analysis proved that present of dual surfactant supported better molecular alignment in PVDF membranes.

\section{Conclusions}

From this study, PVDF/PEG 200 with dual surfactants (SDS/Tween 80, Triton X-100/Tween 80) were

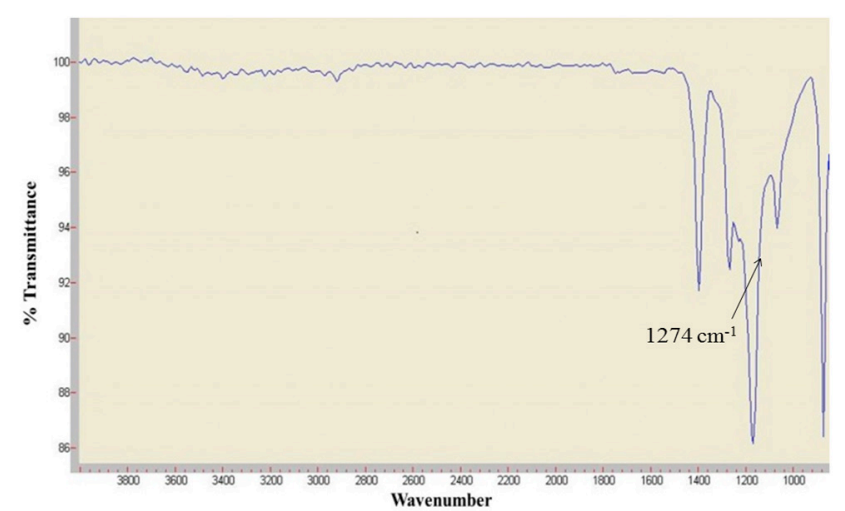

Fig. 6 FTIR spectra of MUF2 membrane (SDS/Tween 80) successfully developed via phase inversion technique. Experimental data revealed that the small amount of dual surfactants $(2 \mathrm{wt} \%$ or $1: 1$ in ratio of Triton X-100/ Tween 80) in the polymeric PVDF/PEG 200 solutions significantly improved the membrane permeability up to $120.84 \mathrm{~L} / \mathrm{m}^{2} \mathrm{~h}$ for permeate flux of BSA protein. Besides, MUF2 membrane produced from SDS/Tween 80 achieved higher protein rejections which are $82 \%$ and $75 \%$ for BSA and EA compared to MUF3. The formation of fine finger-like structure, macro-voids and pores on the top, sub-layer and bottom layer of the fabricated membranes led towards higher membrane porosity and enhanced the membranes performance. FTIR proved that the presence of dual surfactants in the PVDF membranes provided better molecular properties which reflected towards better performances. In conclusion, dual surfactant materials played important roles in determining the membrane performance, morphologies and molecular properties of PVDF membranes for protein separation.

\section{Acknowledgment}

The authors wish to express their gratitude to the Research Management \& Innovation Centre (RMIC), Universiti Sultan Zainal Abidin (UniSZA) for financing the research project under DPU Research Grant Scheme.

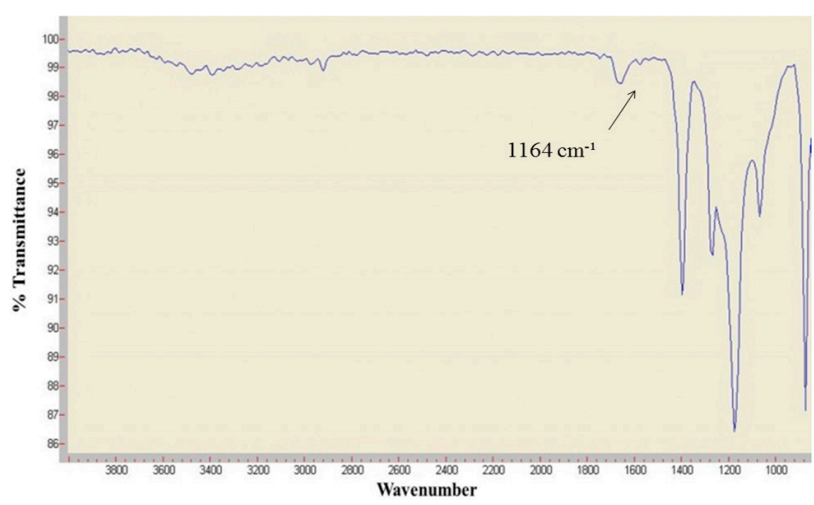

Fig. 7 FTIR spectra of MUF3 membrane (Triton X-100/Tween 80) 


\section{References}

[1] Yunos, K. F. M., Mazlan, N. A., Naim, M. N. M., Baharuddin, A. S., Hassan, A. R. "Ultrafiltration of palm oil mill effluent: Effects of operational pressure and stirring speed on performance and membranes fouling", Environmental Engineering Research, 24(2), pp. 263-270, 2019.

https://doi.org/10.4491/eer.2018.175

[2] Hamzah, N., Rohani, R., Hassan, A. R., Sharifuddin, S. S., Isa, M. H. M. "Development of chitosan/pluronic F108/polyethersulfone (PES) nanofiltration (NF) membrane for oily wastewater treatment", AIP Conference Proceedings, 1972(1), pp. 030014, 2018.

https://doi.org/10.1063/1.5041235

[3] AbdulKadir, W. A. F. W., Yunos, K. F. M., Hassan, A. R., Amin, N. A. M., Baharuddin, A. S. "Fabrication and performance of PSf/CA ultrafiltration membranes: Effect of additives for fouling resistance and selective polyphenol removal from apple juice", BioResources, 14(1), pp. 737-754, 2019. [online] Available at: https://bioresources.cnr.ncsu.edu/resources/fabrication-and-performance-of-psf-ca-ultrafiltration-membranes-effect-of-additives-for-fouling-resistance-and-selective-polyphenol-removal-from-apple-juice/ [Accessed: 09 May 2019]

[4] ALShwayatt, K. A. M., Hassan, A. R., Al-Taani, A. A., Rozali, S., Mohd Safari, N. H., Sulaiman, N. A. "Removal of Arsenic Compound in Jordan, Yarmouk and Zarqa Rivers Using Coagulation Techniques", Indian Journal of Public Health Research \& Development, 10(3), pp. 624-629, 2019.

https://doi.org/10.5958/0976-5506.2019.00571.0

[5] Khairuddin, Z., Juahir, H., Endut, A., Ismail, A., Kamarudin, M. K. A., Ghazali, A., Mokhtar, M., Toriman, M. E., Islam, M. S., Lananan, F. Hassan, A. R. "Moringa Oleifera Dosage Clustering for Remediation Process of Batik Effluents Using Chemometric Technique", International Journal of Engineering and Technology (UAE), 7(3.14), pp. 85-89, 2018. https://oi.org/10.14419/ijet.v7i3.14.16867

[6] Johary, F., Zaimin, F. F. M., Rohani, R., Hassan, A. R., Sharifuddin, S. S., Isa, M. H. M. "Fabrication and characterisation of polyethersulfone/chitosan/non-ionic nanofiltration membrane for dyes removal", AIP Conference Proceedings, 1972(1), Article ID 030017, 2018.

https://doi.org/10.1063/1.5041238

[7] Rambabu, K., Velu, S. "Improved Performance of $\mathrm{CaCl} 2$ Incorporated Polyethersulfone Ultrafiltration Membranes", Periodica Polytechnica Chemical Engineering, 60(3), pp. 181191, 2016.

https://doi.org/10.3311/PPch.8482

[8] Hassan, A. R., Abdul Munaim, M. S. "Fabrication and characterization of integrally skinned-oriented highly selective charged asymmetric low pressure poly(ether sulfone) membranes for nanofiltration", Journal of Chemical Technology and Biotechnology, 87(4), pp. 559-569, 2012.

https://doi.org/10.1002/jctb.2751
[9] Kamarudin, N. A., Kamarudin, M. K. A., Umar, R., Hassan, A. R., Lananan, F., Sunardi "Determination of Filtration and Purification System for Flood Water Filter", International Journal of Engineering and Technology (UAE), 7(2.15), pp. 8-12, 2018. https://doi.org/10.14419/ijet.v7i2.15.11188

[10] Ali, N., Hassan, A. R., Wong, L. Y. "Development of novel asymmetric ultra low pressure membranes and a preliminary study for bacteria and pathogen removal applications", Desalination, 206(13), pp. 474-484, 2007.

https://doi.org/10.1016/j.desal.2006.02.074

[11] Ladewig, B., Al-Shaeli, M. N. Z. "Fundamentals of Membrane Processes", In: Fundamentals of Membrane Bioreactors, Springer, Singapore, 2017, pp. 13-37. https://doi.org/10.1007/978-981-10-2014-8_2

[12] Safari, N. H. M., Hassan, A. R., Che Wan Takwa, C. W. I., Rozali, S. "Deduction of Surfactants Effect on Performance, Morphology, Thermal and Molecular Properties of Polymeric Polyvinylidene Fluoride (PVDF) Based Ultrafiltration Membrane", Periodica Polytechnica Chemical Engineering, 63(1), pp. 27-35, 2019. https://doi.org/10.3311/PPch.12423

[13] Johary, F., Jamaluddin, N. A., Rohani, R., Hassan, A. R., Sharifuddin, S.S., Isa, M. H. M. "Development of polyethersulfone (PES)/silver nanoparticles (AgNPs)/polyethylene glycol (PEG) nanofiltration membrane", AIP Conference Proceedings, 1972(1), Article ID 030022, 2018. https://doi.org/10.1063/1.5041243

[14] Mohd Ali, N. S., Hassan, A.R. "The effect of CTAB and SDS surfactant on the morphology and performance of low pressure active reverse osmosis membrane", Malaysian Journal of Analytical Sciences, 20(3), pp. 510-516, 2016. https://doi.org/10.17576/mjas-2016-2003-07

[15] Gallucci, F., Basile, A., Hai, F. I. "Introduction - A Review of Membrane Reactors", In: Basile, A., Gallucci, F. (eds.) Membranes for Membrane Reactors, John Wiley \& Sons, Ltd, Chichester, USA, 2011, pp. 1-61. https://doi.org/10.1002/9780470977569.ch

[16] Hassan, A.R., Rozali, S., Safari, N. H. M., Besar, B. H. "The roles of polyethersulfone and polyethylene glycol additive on nanofiltration of dyes and membrane morphologies", Environmental Engineering Research, 23(3), pp. 316-322, 2018. https://doi.org/10.4491/eer.2018.023

[17] Hassan, A. R., Sharifuddin, S. S., Isa, M. H. M., Yusra, A. F. I. "Assessment the performance and morphological structures of asymmetric PES/surfactant membranes for nanofiltration of dyes wastewater", Journal of Fundamental and Applied Sciences, 9(2S), pp. 137-146, 2017. https://doi.org/10.4314/jfas.v9i2s.10

[18] Fadilah, N. I. M., Hassan, A. R. "Preparation, Characterization and Performance Studies of Active PVDF Ultrafiltration-Surfactants Membranes Containing PVP as Additive", Advanced Materials Research, 1134, pp. 44-49, 2016. https://doi.org/10.4028/www.scientific.net/AMR.1134.44 
[19] Amirilargani, M., Saljoughi, E., Mohammadi, T. "Effects of Tween 80 concentration as a surfactant additive on morphology and permeability of flat sheet polyethersulfone (PES) membranes", Desalination, 249(2), pp. 837-842, 2009.

https://doi.org/10.1016/j.desal.2009.01.041

[20] Madaeni, S. S., Rahimpour, A. "Effect of type of solvent and non-solvents on morphology and performance of polysulfone and polyethersulfone ultrafiltration membranes for milk concentration", Polymers for Advanced Technologies, 16(10), pp. 717-724, 2005. http://doi.org/10.1002/pat.647

[21] Rahimpour, A., Madaeni, S. S., Mehdipour-Ataei, S. "Synthesis of a novel poly(amide-imide) (PAI) and preparation and characterization of PAI blended polyethersulfone (PES) membranes", Journal of Membrane Science, 311(1-2), pp. 349-359, 2008. https://doi.org/10.1016/j.memsci.2007.12.038

[22] Guillen, G. R., Pan, Y., Li, M., Hoek, E. M. V. "Preparation and Characterization of Membranes Formed by Nonsolvent Induced Phase Separation: A Review", Industrial \& Engineering Chemistry Research, 50(7), pp. 3798-3817, 2011. https://doi.org/10.1021/ie101928r

[23] Sadrzadeh, M., Bhattacharjee, S. "Rational design of phase inversion membranes by tailoring thermodynamics and kinetics of casting solution using polymer additives", Journal of Membrane Science, 441, pp. 31-44, 2013.

https://doi.org/10.1016/j.memsci.2013.04.009

[24] Moghareh Abed, M. M., Kumbharkar, S. C., Groth, A. M., Li, K. "Economical production of PVDF-g-POEM for use as a blend in preparation of PVDF based hydrophilic hollow fibre membranes", Separation and Purification Technology, 106, pp. 47-55, 2013. https://doi.org/10.1016/j.seppur.2012.12.024

[25] Zhang, P.-Y., Yang, H., Xu, Z.-L. "Preparation of Polyvinylidene Fluoride (PVDF) Membranes via Nonsolvent Induced Phase Separation Process Using a Tween 80 and $\mathrm{H}_{2} \mathrm{O}$ Mixture As an Additive", Industrial \& Engineering Chemistry Research, 51(11), pp. 4388-4396, 2012

https://doi.org/10.1021/ie201806v

[26] Sui, Y., Wang, Z., Gao, X., Gao, C. "Antifouling PVDF ultrafiltration membranes incorporating PVDF-g-PHEMA additive via atom transfer radical graft polymerizations", Journal of Membrane Science, 413-414, pp. 38-47, 2012. https://doi.org/10.1016/j.memsci.2012.03.055

[27] Pezeshk, N., Rana, D., Narbaitz, R. M., Matsuura, T. "Novel modified PVDF ultrafiltration flat-sheet membranes", Journal of Membrane Science, 389, pp. 280-286, 2012. https://doi.org/10.1016/j.memsci.2011.10.039

[28] Mansourpanah, Y., Alizadeh, K., Madaeni, S. S., Rahimpour, A., Soltani Afarani,, H. "Using different surfactants for changing the properties of poly(piperazineamide) TFC nanofiltration membranes", Desalination, 271(1-3), pp. 169-177, 2011. https://doi.org/10.1016/j.desal.2010.12.026

[29] Chang, H.-H., Chen, S.-C., Lin, D.-J., Cheng, L.-P. "The effect of Tween-20 additive on the morphology and performance of PVDF membranes", Journal of Membrane Science, 466, pp. 302-312, 2014. https://doi.org/10.1016/j.memsci.2014.05.011
[30] Wang, D.-M., Lin, F.-C., Wu, T.-T., Lai, J.-Y. "Formation mechanism of the macrovoids induced by surfactant additives", Journal of Membrane Science, 142(2), pp. 191-204, 1998. https://doi.org/10.1016/S0376-7388(97)00322-0

[31] Fadilah, N. I. M. "Effect of surfactants on pore structure and pore properties of phase inversion ultrafiltration (UF) membrane", MSc Thesis, Universiti Sains Islam Malaysia, 2015.

[32] Fernández, E., Benito, J. M., Pazos, C., Coca, J. "Ceramic membrane ultrafiltration of anionic and nonionic surfactant solutions", Journal of Membrane Science, 246(1), pp. 1-6, 2005. https://doi.org/10.1016/j.memsci.2004.04.007

[33] Kamerzell, T. J., Esfandiary, R., Joshi, S. B., Middaugh, C. R., Volkin, D. B. "Protein-excipient interactions: Mechanisms and biophysical characterization applied to protein formulation development", Advanced Drug Delivery Reviews, 63, pp. 1118-1159, 2011. https://doi.org/10.1016/j.addr.2011.07.006

[34] Zainal, S. H., Hassan, A. R., Isa, M. H. M. "The effect of polymer concentration and surfactant types on nanofiltration-surfactant membrane for textile wastewater", Malaysian Journal of Analytical Sciences, 20(6), pp. 1524-1529, 2016.

https://doi.org/10.17576/mjas-2016-2006-34

[35] Ma, Y., Shi, F., Ma, J., Wu, M., Zhang, J., Gao, C. "Effect of PEG additive on the morphology and performance of polysulfone ultrafiltration membranes", Desalination, 27, pp. 51-58, 2011. https://doi.org/10.1016/j.desal.2010.12.054

[36] Kim, I.-C., Lee, K.-H. "Effect of poly(ethylene glycol) 200 on the formation of a polyetherimide asymmetric membrane and its performance in aqueous solvent mixture permeation", Journal of Membrane Science, 230(1-2), pp. 183-188, 2004. https://doi.org/10.1016/j.memsci.2003.11.002

[37] Loh, C. H., Wang, R. "Effects of Additives and Coagulant Temperature on Fabrication of High Performance PVDF/Pluronic F127 Blend Hollow Fiber Membranes via Nonsolvent Induced Phase Separation", Chinese Journal of Chemical Engineering, 20(1), pp. 71-79, 2012. https://doi.org/10.1016/S1004-9541(12)60365-6

[38] Buch, P. R., Jagan Mohan, D., Reddy, A. V. R. "Preparation, characterization and chlorine stability of aromatic-cycloaliphatic polyamide thin film composite membranes", Journal of Membrane Science, 309(1-2), pp. 36-44, 2008. https://doi.org/10.1016/j.memsci.2007.10.004

[39] Ziani, K., Henrist, C., Jérôme, C., Aqil, A., Maté, J. I., Cloots, R. "Effect of nonionic surfactant and acidity on chitosan nanofibers with different molecular weights", Carbohydrate Polymers, 83(2), pp. $470-476,2011$. https://doi.org/10.1016/j.carbpol.2010.08.002

[40] Wei, X., Wang, Z., Wang, J., Wang S. "A novel method of surface modification to polysulfone ultrafiltration membrane by preadsorption of citric acid or sodium bisulfite", Membrane Water Treatment, 3(1), pp. 35-49, 2012. https://doi.org/10.12989/mwt.2012.3.1.035 